\title{
Cytoreductive surgery in elderly and senile patients with disseminated forms of colorectal cancer
}

\author{
Maistrenko NA ${ }^{1}$, Sazonov $\mathrm{AA}^{1 *}$ and Hvatov $\mathrm{AA}^{2}$ \\ ${ }^{1}$ Russian Military Medical Academy, Russia \\ ${ }^{2}$ Leningrad Regional Hospital, Russia
}

\section{Introduction}

Nowadays the problem of surgical treatment of colorectal cancer (CRC) is becoming very important due to high speed of increasing morbidity and mortality, which is registered almost in all economically developed countries in the world [1,2]. In 2012, more than one million new cases of CRC were detected on our planet and about half a million-people died from this disease [1]. On the territory of Russia, a primary diagnosis of colorectal cancer is annually established in 6000 people, with the highest incidence rates in the North-West region (St. Petersburg and Leningrad region), where in the general structure of oncopathology, colorectal cancer is in the second [2].

Low efficiency of screening programs does not allow to succeed in solving the problem of timely diagnosis of CRC. Consequently, distant metastases at the time of initial diagnosis are found in more than a third of patients $[3,4]$. In most cases of disseminated colorectal cancer (about $80 \%$ ) secondary foci are detected in the liver, due to anatomical and physiological features of the organ, which is the "first filter" for tumor emboli falling into the portal vein system. Resectability of liver metastases is only $15-20 \%[5,6]$. The average life expectancy of patients with IV stage of CRC without using aggressive surgical tactics, does not exceed 6-8 months $[7,8]$.

The increasing proportion of patients with metastatic CRC, the low effective of chemotherapy, along with growing opportunities for anesthesia and intensive therapy, conduces interest in performing cytoreductive operations $[5,6]$. According to the latest ideas, the removal of the primary tumor, on the one hand, prevents the development hard paratumoral complications, such as obstructive obstruction, bleeding, perifocal inflammation, and perforation that can lead to the death of a patient earlier than the fatal progression of metastatic lesion $[3,8]$. On the other hand, a decrease of tumor cells reduces the concentration of immunosuppressive factors and tumor antigenemia, which leads to the deblocking of its own antitumoral immunity [5,8]. Finally, the reduction of the tumor mass inscreases the sensitivity of the residual tumor to chemotherapy $[6,7]$.

Thus, long-term results of treatment demonstrate the effect of cytoreductive operations in patients with $4^{\text {th }}$ stage of colorectal cancer. However, the implementation of active surgical approach may be associated with a sufficiently high risk of complications, which is connected with a functional reserves of the patient's body because of weakness of immunity and cancer intoxication. According to some authors, the performance of cytoreductive operations is contraindicated in the group of patients with severe concomitant diseases [6,9]. In this regard, it should be noted that a prevailing group of patients with CRC is presented with geriartric patients. The pronounced polymorbidity along with the decrease in the general functional adaptive-compensatory possibilities of the organism naturally lead to a significant increase in the degree of operational-anesthesiological risk of geriatric patients. As a consequence, surgical treatment of patients older than 60 years is accompanied by higher rates of postoperative mortality and complications than in younger patients [9-11]. On the other hand, using of active surgical tactics for gerontological patients with advanced stages of CRC seems to be very justified from the perspective of predicting long-term outcomes, according to the slower progression of the tumor process and the lower probability of early recurrences. Thus, the evaluation of the effectiveness and validity of cytoreductive surgery in patients of older age groups with advanced forms of CRC seems very relevant. In recent years, the number of publications about using cytoreductive operations in CRC and the specificies of surgical treatment of elderly and senile patients has increased. However, in the medical literature available to us, we did not find any reports of the results of cytoreductive surgical procedures in patients of older age groups with disseminated CRC.

Objective: to evaluate the effectiveness of cytoreductive surgical procedures in geriatric patients with $4^{\text {th }}$ stage of colorectal cancer.

\section{Materials and methods}

Cytoreductive operations were performed to 50 patients with $4^{\text {th }}$ stage of CRC from January 2010 to September 2014. All patients have had distant metastases in liver. The surgical tactics included the removal of the primary tumor without affecting to distant metastases. Patients were divided into 2 groups according to age-related factors. The main group of 30 people were elderly and senile patients. The control group was formed from 20 patients younger than 60 years old. The main group included 15 men and 15 women. The average age of patients in this group was $70.2+-3$ years (from 60 to 88 years old). In the control group, there were 9 males and 11 females whose average age was $51.8 \pm 3$ years ( 43 to 58 years). All patients underwent preoperative examination in a hospital setting, the main tasks were to determine the localization of the tumor process, the resectiability of the primary tumor and metastases, as well as the evaluation of the body's functional reserves. In addition to the laboratory-instrumental methods included in the survey standard before the planned operation, the diagnostic program also included: ultrasound, MRI or CT of the abdominal cavity, as well as MRI of the pelvis.

Correspondence to: Sazonov AA, Chair of Faculty Surgery of the Russian Military Medical Academy, Russia; E-mail: sazonov_alex_doc@mail.ru

Received: September 23, 2017; Accepted: October 20, 2017; Published: October 24,2017 
The dominant localization of the primary tumor in both groups was the rectum and sigmoid colon, and in most patients it was locally advanced (77\% in the main and $83 \%$ in the control group). Both groups were compared in the presence of metastases to regional lymph nodes, which were detected in 20 patients of the main group and in 14 patients in the control group. Almost all patients had severe paratumoral complications, significantly worsening their general condition (Table 1). Asymptomatic clinical course of the primary tumor process was noted only in 3 patients in the main and in 4 in the control group.

There were not statistically significant differences in the histological structure of primary tumors between patients. In both groups moderately differentiated adenocarcinomas predominated. Complications of concomitant pathology were much more pronounced in patients of the main group (Table 2).

Almost in all clinical cases were detected multiple bilobar metastases, which excluded the possibility of liver resection. Solitary and single metastases were diagnosed only in 6 patients of the main group. But the implementation of a one-stage combined operation (removal of the primary tumor with liver resection) was not possible because of their extremely grave physical status.

Surgical tactics regarding to the primary tumor growth, despite the palliative nature of the interventions, were based on the observance of all the principles of oncological radicalism. Multiple metastatic liver damage did not influence the decision to perform lymphadenectomy, the volume of which was based on preoperative diagnosis and intraoperative revision. The presence of distant metastases was not considered as a limiting factor in the formation of inter-intestinal anastomoses. The structure of surgical interventions performed in both groups is presented in Table 3.

Analyzing the data given in the table, it can be noted that $26(87 \%)$ patients in the main group and $16(80 \%)$ in the control group managed to restore natural passage of intestinal contents. In both groups, there were 2 clinical cases of a locally advanced primary tumor, which required the implementation of combined interventions.

Systemic chemotherapy after surgical treatment was performed in the majority of patients ( 23 from the main and 14 from the control group). The main schemes were: Mayo and Folfolx. Three patients from the main and two of the control group underwent selective intraarterial chemo-perfusion into the hepatic artery.

\section{Results and discussion}

Evaluation of the nearest postoperative period (30 days from the moment of the operation) was performed in all patients in both groups. The development of complications in the postoperative period was noted in 11 elderly and senile patients (37\% of the total number of patients in the main group). In the control group, this indicator was lower and amounted to $27 \%$. For a comprehensive analysis of the complications of the postoperative period, they were divided into 2 groups. The first group included complications that did not threaten the patient's life, for the resolution of which it was enough to carry out conservative treatment measures (the severity of complications corresponds to 1-2 degrees according to Clavien-Dindo classification). The second group included complications threatening the development of a lethal outcome, for the elimination of which it was necessary to perform repeated surgical interventions or intensive treatment in the intensive care unit (the severity of complications corresponds to 3-4 degrees according to Clavien-Dindo classification). The frequency of development of various complications in both groups of patients is presented in table 4 .
Table 1. Frequency of paratumoral complications.

\begin{tabular}{|l|c|c|}
\hline \multicolumn{1}{|c|}{ Complications } & Main group (n=30) & Control group (n=20) \\
\hline $\begin{array}{l}\text { subcompensated intestinal } \\
\text { permeability }\end{array}$ & 22 & 15 \\
\hline perifocal inflammation & 8 & 6 \\
\hline bleeding & 7 & 4 \\
\hline result & 37 & 25 \\
\hline
\end{tabular}

10 patients in the main and in 7 in the control group have had a combination of several complications

Table 2. The structure of concomitant pathology.

\begin{tabular}{|l|c|c|}
\hline \multicolumn{1}{|c|}{ Diseases } & Main group $(\mathbf{n}=\mathbf{3 0})$ & Control group (n=20) \\
\hline cardiovascular system & 28 & 8 \\
\hline digestive system & 16 & 4 \\
\hline respiratory system & 12 & 2 \\
\hline endocrine system & 9 & 2 \\
\hline urinary system & 8 & 0 \\
\hline result & 73 & 14 \\
\hline
\end{tabular}

17 patients in the main group and 2 in the control group have had a combination of several diseases

Table 3. structure of surgical interventions

\begin{tabular}{|l|c|c|}
\hline \multicolumn{1}{|c|}{ Type of operation } & Main group (n=30) & Control group (n=20) \\
\hline $\begin{array}{l}\text { anterior rectal resection } \\
\text { abdominal perineal }\end{array}$ & 9 & 7 \\
\hline extirpation & 2 & 3 \\
\hline sigmoid resection & 2 & 2 \\
\hline Hartmann's operation & 7 & 3 \\
\hline right hemicolectomy & 1 & 0 \\
\hline left hemicolectomy & 1 & 1 \\
\hline $\begin{array}{l}\text { resection of the transverse } \\
\text { colon }\end{array}$ & 1 & 0 \\
\hline abdominal-anal resection & 1 & 0 \\
\hline $\begin{array}{l}\text { subtotal colectomy } \\
\text { posterior supralevator } \\
\text { exenteration of the pelvis }\end{array}$ & 0 & 1 \\
\hline $\begin{array}{l}\text { combined resection of the } \\
\text { sigmoid colon with resection } \\
\text { of the small intestine }\end{array}$ & 1 & 1 \\
\hline $\begin{array}{l}\text { combined resection of the } \\
\text { sigmoid colon with resection } \\
\text { of the bladder }\end{array}$ & & 0 \\
\hline
\end{tabular}

Table 4. Frequency of postoperative complications

\begin{tabular}{|c|l|c|c|}
\hline \multicolumn{1}{|c|}{ Complication } & $\begin{array}{c}\text { Main group } \\
(\mathbf{n = 3 0 )}\end{array}$ & $\begin{array}{c}\text { Control group } \\
(\mathbf{n = 2 0 )}\end{array}$ \\
\hline \multirow{3}{*}{1 group } & suppuration of a postoperative wound & 5 & 3 \\
\cline { 2 - 4 } & bladder dysfunction & 6 & 6 \\
\cline { 2 - 4 } & lymphorrhea & 4 & 2 \\
\cline { 2 - 4 } & hypostatic pneumonia & 2 & - \\
\cline { 2 - 4 } & deep vein thrombosis & 1 & - \\
\hline \multirow{2}{*}{ group } & failure of intestinal anastomosis & 2 & - \\
\cline { 2 - 4 } & perforation of chronic duodenal ulcer & 1 & - \\
\cline { 2 - 4 } & acute heart failure & 2 & - \\
\cline { 2 - 4 } & acute renal failure & 1 & - \\
\hline
\end{tabular}

7 patients from the main group and 2 from the control group have had combination of two or more complications

The data given in the table shows that the complications of both the first and second groups are more common in patients aged more than 60 years old. With a more detailed evaluation, it becomes evident that the more frequent development of complications in gerontological patients occurs, primarily, due to those of them that are caused by decompensation of the concomitant pathology. At the same time, the 
proportion of complications associated with the implementation of the operational benefit in this group of patients is only slightly higher than in patients younger than 60 years. These data, in our opinion, convincingly demonstrate the importance of a competent approach to assessing the overall status of older patients and timely correction of concomitant pathology in the preoperative period.

In the postoperative period one lethal outcome was recorded in the patient of the main group on the 27th day after performing abdominal anal resection. The cause of death was multiorgan failure, which developed because of cancer intoxication. In the control group there was no 30-day mortality.

The duration of the postoperative period was higher in the main group of patients, reaching 14.5 days, while in the control group it was 11 days. A similar pattern was noted in the evaluation of the length of stay in the intensive care unit, which in elderly and senile patients exceeded the given indicator in the group of patients younger than 60 years and amounted to 2.5 bed days on average.

Long-term results of treatment were evaluated in 45 of 50 patients (24 patients from the main, 18 - from control group) in the period from 12 to 68 months. The median survival time of patients was $29 \pm 1.5$ months in the main and $18 \pm 1.1$ months in the control group. The 3 -year survival was overcome by 9 elderly patients and only one patient from the group of patients younger than 60 years old. Comparison of survival rates in these groups demonstrates a higher efficiency of cytoreductive operations in patients of older age groups. Graphical estimation of the life expectancy of patients in both groups for a 3-year period is shown in Figure 1.

The important criterion of the effectiveness of the surgical treatment performed along with the patients survival rates is an integral assessment of their life quality. According to some authors, the most important expectations for geriatric patients with CRC are not only related with duration of the remaining life but in a greater degree are linked with its quality, including the preservation of the habitual way of life and independence from surrounding. To study the quality of life the SF-36 questionnaire was used. The assessment of life quality was produced in 18 patients of the main group and in 16 of the control group, in the preoperative period, and also in terms of 6 to 12 months after the surgical intervention. The overall quality of life in the late postoperative period was better in patients of the main group (Figure 2).

The highest indicators of the quality of life of elderly and senile patients were noted on such scales as physical and social activity, as well as emotional functioning. 17 Of the 18 patients in the main group who received the questionnaire, ere generally satisfied with the quality of life, did not experience significant restrictions and fully maintained

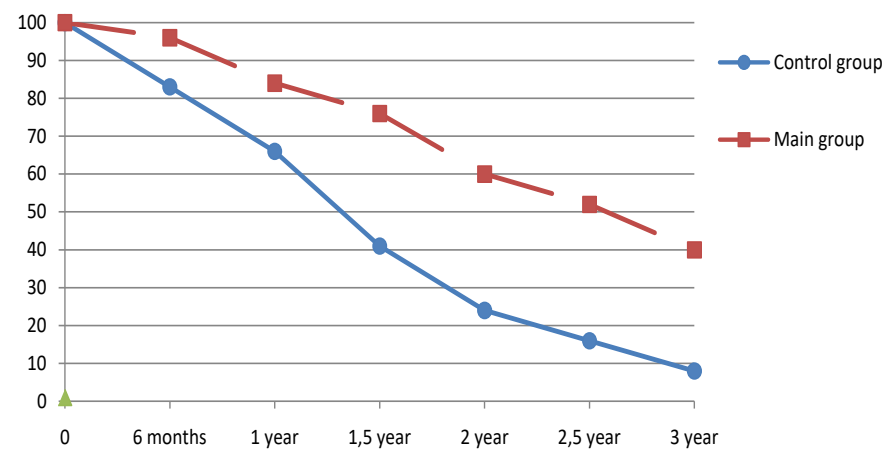

Figure 1. 3-year survival after cytoreductive operations.

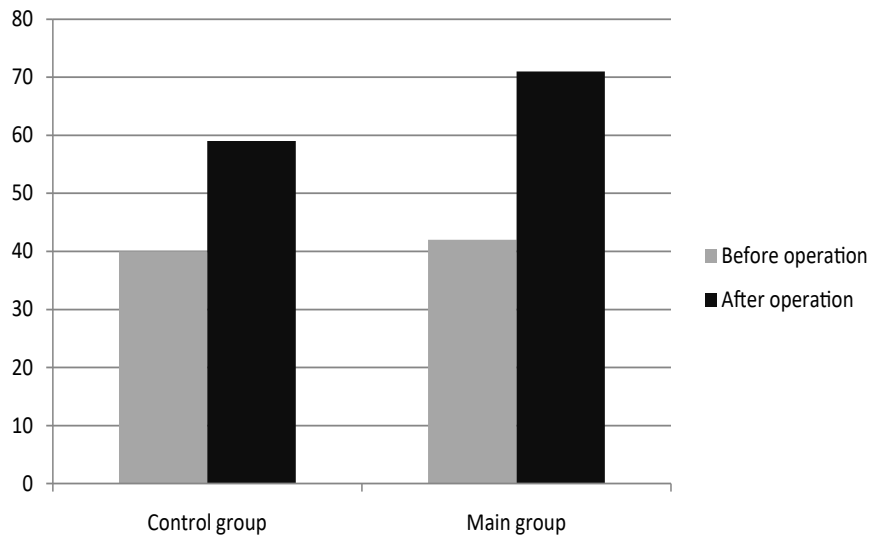

Figure 2. Integral indicators of life quality after cytoreductive operations.

their ability to self-service. Only in one clinical case there were no positive changes in the comparative assessment of the quality of life in the pre-operative period and after 6 months after the performed surgical intervention. However, the unsatisfactory quality of life of this patient, in the first place, was due to severe reactions of the body to ongoing chemotherapy. In all other patients of the geriatric profile, the performance of cytoreductive operations significantly improved the quality of their life.

Finally, using of cytoreductive surgery in geriatric patients with CRC seems to be effective because it provides an opportunity not only to prolong their life but also to increase its quality.

\section{Conclusion}

1. Palliative resection (removal of the primary tumor) in elderly and senile patients with disseminated colorectal cancer allows achieving encouraging long-term results, providing higher survival rates (median - 29 months) than in younger patients (median - 18 months).

2. The more frequent development of complications after cytoreductive operations in geriatric patients is usually associated with decompensation of the age-associated pathology, which confirms the need for its correction in the preoperative period.

3. Removal of the primary tumor in elderly and senile patients with metastatic colorectal cancer provides a significant increase in the quality of their life.

\section{References}

1. Ferlay J, Soerjomataram I, Dikshit R, Eser S, Mathers C, et al. (2015) Cancer incidence and mortality worldwide: sources, methods and major patterns in GLOBOCAN 2012. Int J Cancer 359-386. [Crossref]

2. Kaprin AD, Starinskij VV, Petrova GV (2017) Malignant neoplasm in Russia in 2015 (morbidity, mortality). M.: MNIOI im. P.A. Gercena; filial FGBU «NMIRC» MinzdravaRossii.

3. Aslam MI, Kelkar A, Sharpe D, Jameson JS (2010) Ten years experience of managing the primary tumours in patients with stage IV colorectal cancers. Int J Surg 8: 305-313. [Crossref]

4. Elias D, Glehen O, Pocard M, Quenet F, Goéré D, et al. (2010) A comparative study of complete cytoreductive surgery plus intraperitoneal chemotherapy to treat peritoneal dissemination from colon, rectum, small bowel, and nonpseudomyxoma appendix. Ann Surg 251: 896-901. [Crossref]

5. Ferrand F, Malka D, Bourredjem A, Allonier C, Bouché O, et al. (2013) Impact of primary tumour resection on survival of patients with colorectal cancer and synchronous metastases treated by chemotherapy. Eur J Cancer 49: 90-97. [Crossref] 
6. Muratore A, Zorzi D, Bouzari H, Amisano M, Massucco P, et al. (2007) Asymptomatic colorectal cancer with unresectable liver metastases: immediate colorectal resection or up-front systemic chemotherapy? Ann Surg Oncol 14: 766-770. [Crossref]

7. Rivard JD, McConnell YJ, Temple WJ, Mack LA (2014) Cytoreduction and heated intraperitoneal chemotherapy for colorectal cancer: are we excluding patients who may benefit? J Surg Oncol 109(2): 104-109. [Crossref]

8. Stillwell AP, Buettner PG, Ho YH (2010) Meta-analysis of survival of patients with stage IV colorectal cancer managed with surgical resection versus chemotherapy alone. World J Surg 34: 797-807. [Crossref]
9. Sanoff HK, Goldberg RM (2007) Colorectal cancer treatment in older patients. Gastrointest Cancer Res 1: 248-253. [Crossref]

10. Audisio RA, Papamichael D (2012) Treatment of colorectal cancer in older patients. Nat Rev Gastroenterol Hepatol 9: 716-725. [Crossref]

11. Schmoll HJ, Van Cutsem E, Stein A, Valentini V, Glimelius B, et al. (2012) ESMO Consensus Guidelines for anagement of patients with colon and rectal cancer. a personalized approach to clinical decision making. Ann Oncol 23: 2479-2516. [Crossref]

Copyright: (O2017 Maistrenko NA. This is an open-access article distributed under the terms of the Creative Commons Attribution License, which permits unrestricted use, distribution, and reproduction in any medium, provided the original author and source are credited. 